Om beskattning af aktiebolags vinst och utdelning till delägarne enligt förordningen om inkomstskatt

Author(s): G. F. Ö.

Source: Ekonomisk Tidskrift, Årg. 5 (1903), pp. 433-447

Published by: Wiley on behalf of The Scandinavian Journal of Economics

Stable URL: http://www.jstor.org/stable/3436842

Accessed: 23-06-2016 15:20 UTC

Your use of the JSTOR archive indicates your acceptance of the Terms \& Conditions of Use, available at

http://about.jstor.org/terms

JSTOR is a not-for-profit service that helps scholars, researchers, and students discover, use, and build upon a wide range of content in a trusted digital archive. We use information technology and tools to increase productivity and facilitate new forms of scholarship. For more information about JSTOR, please contact support@jstor.org.

The Scandinavian Journal of Economics, Wiley are collaborating with JSTOR to digitize, preserve and extend access to Ekonomisk Tidskrift 


\section{Om beskattning af aktiebolags vinst och utdelning till delägarne enligt förordningen om inkomstskatt.}

I en uppsats i 9:de häftet af Ekonomisk Tidskrift för detta år har professor Davidson behandlat åtskilliga spörsmål beträffande tolkningen af den nya inkomstskatteförordningen. Då hans uppfattning i flere afseenden torde skilja sig från såväl de skattskyldiges som beskattningsmyndigheternas föreställningar om, huru taxeringen rätteligen skall ske, har jag önskat framhålla de skäl, som tala för spörsmålens besvarande $\mathrm{i}$ annan riktning än som af hr Davidson angifvits. Möjligen kan genom meningsutbyte något större klarhet vinnas i dessa ganska invecklade frågor.

Rubriken för hr Davidsons uppsats är: "frågor rörande beskattningen af aktiebolags vinst", men han berör i densamma flere andra frågor af största vikt. Jag skall upptaga dem till behandling hvar och en för sig.

I) Skall inkomst af kapital taxeras till det belopp, hvartill inkomsten uppgått under det föregående året, d. v. s. det belopp, som uppgifvits i en riktigt affattad själfdeklaration, eller äga taxeringsmyndigheterna upptaga inkomsten af kapital till det belopp, de kunna beräkna, att inkomsten kommer att utgöra under det lopande året?

Hufvudstadgandet härom $\mathrm{i}$ inkomstskatteförordningen lyder sålunda: "Inkomst af kapital och annan inkomst af arbete än lön eller pension upptages med det belopp, hvartill inkomsten -under nästföregående året uppgått", och är ordagrannt upptaget från bevillningsförordningen. 
Om man nu frågar, huru stadgandet tillämpats vid bevillningstaxeringen, lärer svaret blifva, att man icke kan fastslå, att någon bestämd princip gjort sig gällande. Där en person eller bolag lämnat uppgift om sin inkomst under föregående år, hvilken af taxeringsmyndigheten tagits för god, har nog inkomsten taxerats till det uppgifna beloppet. Men i andra fall, där man haft att hålla sig till hvad man kunnat få veta genom utomstående personer eller till rena gissningar, torde man vanligen icke reflekterat öfver huruvida inkomstberäkningen skulle motsvara det föregående årets eller det löpande årets inkomst. Detta har varit helt naturligt, då man icke ägt någon bestämd kännedom om beloppet vare sig för det ena året eller det andra. Har den skattskyldige erhållit någon ny inkomstkälla, t. ex. genom arf eller på grund af fast egendoms försäljning, eller har inkomst af kapital gått förlorad, t. ex. genom förluster på gäldenärer eller genom placering $\mathrm{i}$ fastighet, har detta iakttagits vid taxeringen. Detta öfverensstämmer med förordningens bestämmelse »att inkomsten, första året den åtnjutes äfvensom då den icke åtnjutits för hela föregående året, skall upptagas med det belopp, hvartill densamma, enligt de upplysningar taxeringsmännen kunna förskaffa sig, skäligen må anses för det löpande året uppgå s samt "att då inkomsten under det löpande året upphör, densamma upptages med det belopp, som, med det nästföregående årets inkomst till beräkningsgrund, motsvarar den tidrymd af det löpande året, för hvilken inkomsten åtnjutes».

Det är tydligt stadgadt i bevillningsförordningen, att inkomst af ny inkomstkälla skall upptagas till det belopp, hvartill den anses uppgå för det löpande året, och samma bestämmelse skall också gälla för inkomstskatten. Men då har man att söka göra klart för sig, hvad som menas med ny inkomstkälla. $\mathrm{Hr}$ Davidson yttrar i noten sid. 368 , att hvarje särskild aktie måste betraktas såsom en särskild inkomstkälla. Häraf kan man sluta, att han besvarar frågan på det sätt, att hvarje särskildt värdepapper är en särskild inkomstkälla. Om en person under år 1902 ägde aktier för 20,000 och därå uppbar utdelning med I,200 kronor, men $\mathrm{i}$ slutet af året sålde dessa aktier och $\mathrm{i}$ stället inköpte andra för den erhållna köpesumman, så skall vid 1903 års taxering vederbörande myndighet anse, att han förlorat en inkomst- 
källa och erhållit en ny, och sålunda taxera honom icke för den inkomst, han hade under 1902, utan för den inkomst, han förmodas komma att erhålla under år 1903 af de nyinköpta aktierna. Eller om han gjorde nämnda omplacering den I april 1903, skulle taxeringsmyndigheten dels upptaga $1 / 4$ af den under 1902 uppburna utdelningen, dels ock $3 / 4$ af hvad inkomsten å de nya aktierna antages komma att utgöra. Alldeles detsamma skulle gälla vid omplacering af utlånade medel, enär hr Davidson förklarar, att samma regler skola tillämpas $\mathrm{i}$ fråga om utdelning å aktier och $\mathrm{i}$ fråga om inkomst å kapital. Således om jag vid årsskiftet inkasserar en fordran och insätter pengarna på deposition eller upp- och afskrifning i afvaktan på annan placering, skulle man ej fästa sig vid deklarationen, som anger inkomsten under det förflutna året, utan rätta sig efter den ränta, som erhålles å depositionsbeviset eller upp- och afskrifningsräkning; och detsamma skulle naturligtvis gälla vid hvarje omplacering af ett utlånadt kapital, liksom vid hvarje försäljning eller köp af aktier.

Men kan en sådan taxeringsmetod verkligen vara riktig och afsedd af riksdagen? Enligt min mening har den varit oriktig redan vid taxering efter bevillningsförordningen, och vid taxering efter inkomstskatteförordningen anser jag den absolut omöjlig.

Då bevillningsförordningen säger, att inkomst af kapital skall upptagas med inkomstens belopp under föregående året, har efter all rimlighet meningen varit den, att om en persons utlånade kapital varit oförändradt, inkomsten skall upptagas med förra årets inkomstbelopp, oberoende huru det må hafva omplacerats under förra året eller det löpande året, hvaremot, om den skattskyldige förvärfvat eller förlorat kapital, vederbörlig höjning eller sänkning af taxeringen borde äga rum. Nog är det antagligt, att såväl allmänheten som taxeringsmyndigheterna i regel så tolkat förordningen.

Men om man också skulle tänka sig den af hr Davidson anvisade tolkningen såsom möjlig, då det gäller bevillningsförordningen, borde den icke kunna vidhållas, då det gäller inkomstskatteförordningen.

Införandet af själfdeklarationen $i$ vår skattelagstiftning måste uppenbarligen gifva en helt ny prägel åt hela taxeringsförfarandet. 
Taxeringen för inkomst enligt inkomstskatteförordningen måste rätta sig efter de af den skattskyldige uppgifna siffrorna, om de ej befinnas oriktiga, och skall ej frångå dessa siffror i andra fall, än då nya omständigheter tillkommit, hvilka enligt förordningens uttryckliga föreskrift föranleda frångående af deklarationen. Hvartill skall det tjäna att i själfdeklarationen uppgifva inkomstens belopp under det förflutna året, om taxeringsmyndigheten skulle på grund af hvarjehanda gissningar om förändringar under det löpande året fastställa helt annat belopp? Den som ärligt och $\mathrm{i}$ öfverensstämmelse med gällande förordning afgifver sin själfdeklaration, gör anspråk på att taxeringen skall rätta sig därefter, men skulle det gång efter annan visa sig, att vederbörande bestämma helt andra siffror, blir helt säkert resultatet, att den skattskyldige förlorar både intresset och känslan af ansvar och att hela institutet råkar i misskredit hos allmänheten.

Man kan därför med allt skäl göra gällande $\mathrm{i}$ fråga om inkomst af kapital, d. v. s. inkomst af utlånade penningar samt utdelning å aktier, att inkomsten upptages till förra årets inkomst, så vida det inkomstgifvande kapitalet ej undergått förändring genom kapitalförvärf eller kapitalförlust, och alldeles oberoende af huruvida kapitalet undergått omplacering eller räntefoten undergått förändring. Undantagsstadgandet i $5 \$ 2$ mom. a) att inkomst, som icke åtnjutits under hela föregående året, skall upptagas med det belopp, hvartill den anses uppgå under det löpande året, bör, hvad taxering enligt inkomstskatteförordningen angår, tillämpas så restriktivt som möjligt, så att man frångår en riktigt afgifven deklaration endast $\mathrm{i}$ det fall, då den skattskyldige förvärfvat något nytt kapital eller afhändt sig kapital, som under förra året gaf inkomst.

Hr Davidson utvecklar sin ståndpunkt hufvudsakligen genom att behandla frågan om beskattning af utdelning å aktier. Han anser, att hvarje särskild aktie skall anses såsom en särskild inkomstkälla, att inkomst af aktie, som ägts under hela föregående året och fortfarande äges, skall upptagas med det belopp, hvartill utdelningen uppgått under föregående året, men att under förra året uppburen utdelning å aktie, som sedermera sålts, icke skall taxeras, att om aktie sålts den 2 januari under löpande året, den förre ägaren, som uppburit och deklarerat utdelningen för 
förra året, icke skall taxeras för denna inkomst, men den nye ägaren däremot taxeras för inkomst af aktie, hvarvid taxeringsmyndigheten äger beräkna, hvilken utdelning som kan förväntas under löpande året. Han går så långt $\mathrm{i}$ fordran på detaljering vid inkomstberäkningen, att han förklarar, att en och samma person samma år kan taxeras för olika utdelning för olika aktier $\mathrm{i}$ samma bolag.

Hvad som vid en sådan taxeringsmetod först faller $\mathrm{i}$ ögonen, är, att den är opraktisk, omöjlig att tillämpa och ägnad att åstadkomma ett oändligt trassel.

Med vår tids rörliga förhållanden företager hvarje affärsman ständiga omflyttningar af sitt kapital; köp och försäljningar af aktier höra till ordningen för dagen. Detsamma gäller för en stor del förmögna personer, som ej egentligen tillhöra affärsmännens klass, men finna förhållandena föranleda omplacering af kapitalet till större eller mindre del hvarje år. Huru skola taxeringsmyndigheterna kunna uträkna det rätta inkomstbeloppet, om de skola tillämpa hr Davidsons regler? Deklarationerna gifva icke behöfliga upplysningar. De innehålla en klumpsiffra för inkomsten af kapital - efter afdrag af skuldräntor - under förra året, men de angifva icke, hvilka värdepapper den skattskyldige äger eller under förra året ägde, och ännu mindre, hvilka omplaceringar han gjort eller tiden därför. Det är alltså för taxeringsmyndigheterna omöjligt att finna hållbara grunder för taxeringen, om man anser sig skyldig att gå till väga på det angifna sättet. Det kan väl icke vara någon tanke på att bevillningsberedningarne skulle infordra uppgifter från de skattskyldige rörande alla detaljerna $\mathrm{i}$ deras affärer; åtminstone har aldrig något sådant varit afsedt. Det är af största vikt vid en taxering, som grundar sig på själfdeklaration, att man har att hålla sig till alldeles bestämda klara uppgifter och att ingenting eller så litet som möjligt lämnas åt taxeringsmyndigheternas godtycke. Denna fordran är ovillkorlig och framstår allra skarpast, då man erinrar sig, att med systemet är förenadt progressiv beskattning, som kan flerdubbla hvarje begånget misstag.

Jag vill därför bestämdt göra gällande den mening, att taxeringsmyndigheterna icke hafva att ingå på undersökning om huru en skattskyldig omplacerat sin förmögenhet, utan helt en- 
kelt rätta sig efter deklarationen, sedan man funnit den tillförlitlig, och däri ej göra andra förändringar än som föranledas därigenom, att den skattskyldiges inkomstgifvande kapital ökats eller minskats, hvarom den skattskyldige bör lämna upplysning genom sin deklaration eller eljest.

Till belysande af hvad ofvan sagts, skall jag framlägga ett exempel på taxeringen enligt olika förfaringssätt.

X. har vid I 902 års början:

Obligationer $4 \%$ IOO,OOO

Reverser $5 \% \frac{1}{2} \%_{0}$ 100,000

Aktier i bol. A. IOO,000

D:o b bol. B. $100,000 \quad 400,000$

Skulder $5 \%$

Han köpte 1/7 I902 aktier i aktiebol. C. för I00,000 och upptog lån $5 \%$ å IOO,000

Sålde $1 / 10$ s. å. aktier i aktiebol. A. för IOO,000 och betalte lånet af $1 / 7$ 100,000 Inkasserade ${ }^{31 / 12}$ s. å. reverser IOO,000 Köpte samma dag fastighet för 100,000

Inkomster under 1902 voro:

Ränta å obligationer 4,000

D:o 》 reverser 5,500

Utdelning å aktier A. 6,000 D:o \& d:o

$B$. 7,000 22,500

afgår ränta å I 50,000 7,500

\. 100,000, 3 mån.

I deklarationen uppgifver $\mathrm{X}$. sin inkomst af kapital till kronor I 3,750 utan någon specifikation, men gör anmärkning, att hans räntebärande kapital minskats med I00,000 kronor genom fastighetsköp den 3 I dec. I9O2, hvarför han begär, att inkomsten må nedsättas med 6,00o kronor till 7,750 kronor.

Enligt min åsikt hafva taxeringsmyndigheterna i första hand att pröfva, huruvida man kan anse deklarationen vara ärlig, och om därvid icke göres någon anmärkning, böra de icke frångå deklarationen, såvida de icke tilläfventyrs finna, att den begärda 
nedsättningen af 6,000 kronor med afseende å ränteförhållandena bör jämkas t. ex. till 5,000 kronor, i hvilket fall taxeringen bestämmes till 8,750 kronor.

Huru skulle nu taxeringen ske, enligt hr Davidsons taxeringsmetod?

Inkomst af obligationerna I00,000 kr., som finnas kvar, upptages till 4,000

Reverserna I00,000 kr. äro betalda, inkomst af dem upptages ej

Aktier i bol. A. sålda, inkomst upptages ej

D:o " d:o B. I00,00o kr., inkomst upptages till

D:o " d:o C., inkomst skall upptagas efter hvad man 7,000 väntar skall utdelas 1903 ; bolaget lämnade föregående år $3 \%$, man vet ingenting om den blifvande utdelningen, men tycker, att det borde blifva $5 \%$, och taxerar därför 5,000 I 6,000 hvarifrån afgår $5 \%$ ränta å $\mathrm{I} 50,000 \mathrm{kr}$. 7,500 Kronor 8,500

Detta kan ju tyckas godt och väl, men taxeringsnämnden kan icke äga kännedom om någon af de transaktioner, som utgöra grunden för beräkningen, kan icke veta, att X. sålt sina aktier i bolaget $\mathrm{A}$. och köpt andra i bolaget $\mathrm{C}$. och kan icke veta, huru hög ränta $X$. får betala på sitt lån. Men om taxeringsnämnden frångår deklarationen, är det dess skyldighet enligt $34 \$ .3 \mathrm{mom}$. att tydligen angifva skälen därtill och därom underrätta den skattskyldige.

Enligt det senast omförmälda beräkningssättet skulle man för så godt som alla, som äga större kapital, nödgas frångå deklarationen och verkställa uträkningar på grund af uppgifter, som man söker inhämta från olika håll, men som torde blifva skäligen osäkra. Att tydligen angifva skälen blefve helt visst $i$ de flesta fall omöjligt.

Taxeringsmyndigheterna lära därför gå riktigast tillväga, om de vid taxeringen hålla sig till de belopp, som angifvas i de skattskyldiges deklarationer, där ingen anmärkning mot dessas tillförlitlighet förekommer. 
2) Är all utdelning från aktiebolag beskattningsbar eller är detta beroende af huruvida bolaget gjorde utdelningen af vinstmedel, hvarför bolaget själft är skattskyldigt, eller af andra bolagets tillgångar t. ex. kapitalförvärf, hvarför skatt ej skall betalas?

$\mathrm{Hr}$ Davidson är tveksam i denna fråga, men anser öfvervägande skäl tala för den senare tolkningen. Han anför till stöd därför I $6 \llbracket$ af instruktionen till bevillningsförordningen, som förklarar, att delägarne i bolag icke skola taxeras för inkomst från bolaget, enär bolaget skall erlägga bevillning både för ränteinkomsten af hela det i bolaget nedlagda kapitalet och för den vinst, som rörelsen därutöfver lämnar, och anser, att däri finnes uttalad den uppfattning, att utdelningarna till delägarne utgöra delar af bolagets inkomst och att således den beskattningsbara inkomst, som delägarne uppbära från bolaget, ej kan vara större än bolagets beskattningsbara inkomst.

Äfven om ingenting vore att invända mot denna tolkning af den åberopade $16 \$ \mathrm{i}$ instruktionen, vill jag framhålla, att man alldeles icke har rätt att i fråga om tillämpningen af inkomstskatteförordningen draga slutsatser från nämnda bestämmelse $\mathrm{i}$ instruktionen. Bevillningsförordningen lämnar utdelning å aktier skattefri, och I6 $₫ \mathrm{i}$ instruktionen har intet annat ändamål än att tydligt påpeka detta för beskattningsmyndigheterna. Att då från de ordalag, som användas för att göra detta klart för den, som tillämpar bevillningsförordningen, draga slutsatser $i$ afseende å tolkningen af en annan förordning, som alldeles tvärtom stadgar, att utdelning å aktier skall beskattas, synes föga rimligt.

I inkomstskatteförordningen står helt kategoriskt, att till inkomst af kapital räknas utdelning å aktier i inhemska aktiebolag och å lotter i enskilda bankbolag, utan att antydan göres om någon inskränkning $\mathrm{i}$ skattskyldigheten. Man har ej rätt att förstå detta stadgande på annat sätt, än att allt, som utdelas från bolaget, intill dess i sammanhang med bolagets upplösning själfva kapitalet utdelas, är beskattningsbart.

Till grund för aktiebeskattningen ligger den uppfattningen, att utdelningen å aktierna är en inkomst för aktieägarne, alldeles oberoende af bolagets inkomst. Det åskådningssätt rörande detta ämne, som tagit sig uttryck i inkomstskatteförordningen, är ett helt annat än det, som var gällande på den tiden, då instruktionen 
till bevillningsförordningen skrefs, och man kan därföre icke åberopa denna, då det gäller att afgöra, huru aktieutdelning skall beskattas.

3) Är utdelning beskattningsbar under det år, då den fastställes, eller under det år, då den får lyftas?

$\mathrm{Hr}$ Davidson hyser den förra meningen under åberopande af analogi med andra inkomster, såsom lön, hvilken beskattas för det år, den intjänas, äfven om utbetalningen sker senare, eller ränta, som anses såsom inkomst för det år, under hvilken den är upplupen, äfven om den senare förfaller till betalning. Bodin och Palmgren åter säga, att $\mathrm{i}$ deklarationen skall uppgifvas utdelning, som blifvit tillgänglig till lyftning under nästföregående kalenderår.

Förordningen har ej närmare bestämt detta, men nog synes den senare tolkningen mera antaglig. Utdelningen är ju icke en inkomst för aktieägaren, förr än den får lyftas. Analogien med löner och räntor kan ej vara afgörande, då dessa grundlägga en fordringsrätt, men ej så ett beslut om utdelning. Då i deklarationsformuläret heter: "Undertecknads inkomst af ifrågavarande slag nästföregående år har icke öfverstigit», lärer ingen deklarationsskyldig kunna förstå, att han därvid skall uppgifva utdelning, som visserligen beslutades förra året, men inflyter först under löpande året.

Frågan har icke så stor praktisk betydelse, då det sällan torde förekomma, att utdelning ej får lyftas under det år, då den beslutas.

4) Hvem skall taxeras för utdelning å aktier, som ombytt ägare, den som ägde aktien, då utdelningen bestämdes, eller den som ägde aktien, då utdelningen får lyftas?

$\mathrm{Hr}$ Davidson anser, att om utdelningen ej får lyftas, förr än en tid efter det utdelningen fastställts, åligger skattskyldigheten för aktien den, som ägde aktien, då utdelningen fastställdes, och icke den, som äger aktien, då utdelningen förfaller till utbetalning. Detta yttrande står emellertid i strid med hans uppfattning om taxeringsförhållandet $\mathrm{i}$ det hela. Antag, att utdelningen bestämts den I juni och utbetalats den I augusti r 902 och att $A$ sålt ett parti aktier till $B$ den $I$ juli samma år. Då enligt hr Davidsons mening hvarje särskild aktie är en särskild 
inkomstkälla och A vid taxeringen år I903 icke längre äger dessa aktier, skulle han icke kunna beskattas för utdelningen å desamma, men däremot $B$ såsom nuvarande ägare beskattas för det belopp, hvartill man kunde kalkylera den blifvande utdelningen under år 1903 .

Men om man nu icke godkänner ett sådant sönderdelande af inkomsten, utan utgår från att det är den samlade inkomst, hvilken uppburits under föregående år, som skall deklareras och taxeras, så synes det otvifvelaktigt, att förordningens mening är, att den, som uppburit utdelningen, skall beskattas därför. En tämligen påtaglig anvisning $\mathrm{i}$ detta afseende lämnas i inkomstskatteförordningen $25 \mathbb{b}$ ) I:o), där det föreskrifves, att aktiebolag skall uppgifva namn på delägare, som uppburit eller ägt uppbära utdelningen, ty eljest skulle bolaget ålagts att uppgifva namn på dem, som ägde aktier i bolaget, då utdelningen bestämdes. Det är svårt att förstå, hvarföre detta, såsom hr Davidson yttrar, skulle vara omöjligt. Bolaget kan ju icke uppgifva andra personer såsom ägare af aktier än dem, som hos bolaget anmälts såsom sådana, och det kan icke vara svårare att ur registret öfver aktieägarne lämna uppgifter för den ena dagen än för den andra. Anmälan om aktieägarne åligger enligt 25 \endast sådant aktiebolag, därifrån utdelning på grund af lag eller bolagsordning icke får uppbäras af annan än den, som i behörig ordning styrkt sin rätt till aktien, och det är tydligt, att endast den, som är registrerad för aktien, äger uppbära utdelning.

Skulle ett annat förfarande äga rum i vissa bolag, är sådant oegentligt och måste vid taxeringen föranleda missförstånd. Då faktisk ägare af aktie $i$ strid med gällande bestämmelse $i$ bolagsordningen fått uppbära utdelning utan att vara inregistrerad, lärer det vara en plikt för honom att $\mathrm{i}$ deklarationen meddela detta, liksom det i sådant fall bör vara angeläget för den förre ägaren att lämna taxeringsmyndigheterna $\mathrm{i}$ sin ort kännedom härom.

Men oafsedt den påtagliga anvisning om riksdagens mening, som lämnas af den anförda bestämmelsen i inkomstskatteförordningen, måste det förefalla riktigare, att den, som uppburit inkomsten, skattar därför än att den, som icke uppburit inkomsten, skulle göra det.

Hr Davidson afvisar såsom alldeles ohållbar tanken på 
att beskatta den, som vore ägare till aktien, då utdelningen faktiskt lyftades, ej då den blef tillgänglig till lyftning. Alldeles orimligt vore väl ej ett sådant förfarande, men oafsedt att man ej brukar låta förfallna kuponger medfölja vid aktieförsäljningar, kan erinras, dels att det är den, som äger aktierna, då utdelningen blir tillgänglig, som har rättigheten att uppbära utdelningen, dels att en ny ägare $\mathrm{i}$ ifrågavarande fall med allt skäl kan anses uppbära utdelningen för den förre ägarens räkning.

5) Då vid taxering af aktiebolags inkomst afdrag skall ske för den till aktieägarne bestämda utdelningen, dock icke för mera än 6 procent å inbetaldt aktiekapital, afser detta den utdelning, som fastställdes förra året, eller den, som fastställes under löpande året?

Då formuleringen af uppgiften i deklarationsformuläret lyder sålunda: "Som utdelningen utgjort . . . . k kronor eller . . . . procent å inbetalda kapitalet, utgörande ..... kronor, uppgår berörda afdrag till .....", synes det, som om meningen varit, att afdraget skall ske med belopp, motsvarande den redan förra året verkställda utdelningen. Man kan emellertid sätta i fråga, huruvida det icke snarare borde vara den utdelning, som bestämmes under det Jöpande året på grund af förra årets bokslut, då det ju måste vara riktigast, att den beskattade vinsten och afdraget afse samma år. Hr Davidson tager för gifvet, att det senare är det rätta. Däremot kan dock invändas, att i många fall utdelningen ej är bestämd vid tiden för taxeringen, och det kan ej gå för sig att göra afdrag för hvad taxeringsmyndigheterna förmoda angående den blifvande utdelningen, då man ej kan taxera på rena gissningar. Man skulle kunna gå så till väga, att man afdrager den under löpande året bestämda utdelningen, såvida den är fastställd före taxeringsförrättningen, men $\mathrm{i}$ annat fall den under förra året bestämda utdelningen. Det är svårt att i denna fråga uttala en bestämd mening; dock synes det sistnämnda förfaringssättet kunna förordas som mest praktiskt, ehuru det kan leda till inkonsekvenser.

Men hvad som är afgjordt oriktigt är hr Davidsons uttalande, att ett dylikt afdrag bör få åtnjutas äfven första året, ett aktiebolag är $\mathrm{i}$ verksamhet, hvarvid afdraget skall rättas efter den blifvande utdelningens sannolika belopp. Detta afser det fall, 
att taxeringsmyndigheten på grund af $5 \$ 2$ mom. a) uppskattar ett nytt bolag till det belopp, hvartill inkomsten anses för det löpande året uppgå, utan stöd af ett föregående års resultat. Här kan intet beslut om utdelning förekomma under det löpande året, utan först under det följande året. Att under sådana förhållanden medgifva afdrag för en utdelning, som alldeles sväfvar i luften, saknar tydligen allt stöd i inkomstskatteförordningen.

Praktiskt sedt innebär detta ingen synnerlig obillighet mot aktiebolagen, då nya aktiebolag sällan lämna utdelning för första året.

6) Huru skall förfaras vid s. k. gratisutdelning af nya aktier i aktiebolag?

Om ett aktiebolag förvandlar sin dispositionsfond till nya aktier, hvilka fördelas mellan förutvarande aktieägarne, får det ökade aktiekapitalet icke tagas i betraktande vid bestämmandet af bolagets afdrag. Detta är klart, liksom ock att de till aktieägarne utlämnade nya aktierna icke kunna anses såsom någon utdelning, då de gamla och nya aktierna tillsammans ej äga större värde, än de gamla hade före den nya emissionen.

Såsom gratisutdelning af aktier lärer ock böra betraktas, om nya aktier tecknas af de gamla aktieägarne och motsvarande belopp utdelas af bolagets disponibla medel under ett och samma år.

Men det finnes sätt att kringgå författningens mening, hvilka icke behandlas af hr Davidson. Man kan tänka sig, att ett bolag ett år gör en extra utdelning af $50 \%$ och följande år låter aktieägarne teckna en aktie för två gamla, eller tvärtom, att bolaget ett år låter aktieägarne teckna och betala nya aktier och följande år gör motsvarande utdelning. Eller också kan bolaget mera försiktigt göra en extra utdelning, $t$. ex. under tre år af I00,000 kr. om året, och sedan låta aktieägarne teckna nya aktier å $300,000 \mathrm{kr}$. eller tvärtom låta aktieägarne teckna och inbetala nya aktier och sedan göra en motsvarande extra utdelning, fördelad på flere år. Man kan vidare tänka sig, att de disponibla fonderna under form af vanlig utdelning fördelas mellan de gamla aktieägarne och ny aktieteckning göres af personer, som icke förut ägt någon del $\mathrm{i}$ bolaget.

Huru man skall $\mathrm{i}$ sådana fall bestämma bolagets verkligen inbetalda kapital med afseende å det ifrågavarande afdraget, får 
väl af taxeringsmyndigheterna afgöras efter de omständigheter, som $\mathrm{i}$ hvarje fall föreligga, och de upplysningar de kunna förskaffa sig. Själfva bestämmelsen om beräkningen af afdraget är ägnad att framkalla försök att kringgå densamma och lärer därföre få anses mindre välbetänkt.

Hvad åter angår aktieägarnes skattskyldighet för utdelningar, afsedda att bereda tillgång till ny aktieteckning, synes det otvifvelaktigt, att så snart bolaget formligen beslutit utdelning $\mathrm{i}$ penningar eller varor, äro aktieägarne skattskyldige för hela sin utdelning, äfven om de använda penningarne till ny aktieteckning och aktieteckningen förklaras icke medföra verkligt tillskott till aktiekapital. Förordningen medger icke under några villkor befrielse från skatt för utdelning å aktier.

$\mathrm{Hr}$ Davidson erinrar, att, om aktiekapitalet nedsättes, det minskade kapitalet är bestämmande för afdragets storlek. Däremot är svårt att förstå hans yttrande, att detsamma gäller, om bolaget lidit sådana förluster, att någon del af aktiekapitalet gått förloradt, och detta oberoende af huruvida hvad i lagen om aktiebolag stadgas för detta fall iakttagits. I sistnämnda fall får ju utdelning icke ske, och afdrag kan således ej ifrågakomma.

7) Huru skall utdelning å aktier i utländska bolag beskattas?

Hr Davidson framställer i slutet af sin uppsats den frågan, huruvida sådan utdelning skall beskattas $\mathrm{i}$ de fall, då bolagen själfva äro skyldiga erlägga skatt i Sverige för sin inkomst.

Enligt hans mening bör utdelning från sådana bolag vara fri från bevillning på grund af samma skäl, som varit bestämmande för att medgifva skattefrihet för utdelning från inhemska bolag, eller att bolaget genom bevillningen betalar skatten för aktieägarnes inkomst.

Det är, dock att märka, att bevillningsförordningen icke talar särskildt om utdelning från utländska bolag och därföre naturligtvis ej heller lämnar någon undantagsbestämmelse för vissa af sådana aktier. Det synes då icke möjligt att göra någon skillnad mellan olika slag däraf, hvarföre riktigast torde vara, att bevillning erlägges för utdelning från alla aktier i utländska bolag utan hänsyn till bolagens egen skattskyldighet. Huru man i praxis hittills förfarit, är mig icke bekant, men det förefaller sannolikt, 
att man ej gjort sådan skillnad, som hr Davidson anser böra ske.

Hvad beträffar inkomstskatten, är det uppenbart, att all utdelning å främmande aktier skall beskattas; därom kan icke finnas någon meningsskiljaktighet.

Att utdelning å aktier i utländska bolag räknas såsom inkomst af arbete, är naturligtvis en oegentlighet, som bör så snart som möjligt rättas. Orsaken därtill, att inkomstskatteförordningen upptagit denna bestämmelse från bevillningsförordningen, är den, att man icke kunde låta de skattskyldige vid afgifvande af deklarationen sammanslå utdelning å svenska aktier och utdelning å utländska aktier, enär bevillning icke erlägges för den förra, men väl för den senare, och man ansåg betänkligt att öka uppgifterna $\mathrm{i}$ deklarationen med en ny rubrik, utdelning å aktier i utländska aktiebolag. Man föredrog därföre att behålla den gamla praxis att räkna sådan utdelning till inkomst af arbete, men gjorde till ledning för vederbörande en särskild anmärkning därom i deklarationsformuläret.

Erfarenheten har visat, att tillämpningen af inkomstskattelagar alltid är förenad med betydliga svårigheter. Detta är också ganska förklarligt, då själfva författningen måste inskränka sig till att angifva allmänna regler för taxeringen och omöjligen kan lämna detaljerade föreskrifter, som kunna hänföras till hvarje i verkligheten förekommande fall. Praxis har därföre måst utfylla hvad som varit oklart i författningen.

Svårigheten vid tolkningen af våra förordningar om bevillning och inkomstsskatt ökas särskildt därigenom, att i dem ej finnes någon genomförd princip. I sådant afseende må erinras, att inkomst af fast egendom och af jordbruksrörelse icke uppskattas efter hvad den i verkligheten utgjort, utan efter visst förhållande till egendomens taxeringsvärde, att inkomst taxeras än efter förhållandena under föregående år, än efter beräkning af hvad den kan komma att utgöra under det löpande året och att enligt bevillningsförordningen rättigheten till afdrag för räntor och förluster ställer sig olika för olika inkomstarter. Man kan därföre icke uppställa några ledande principer, hvarefter de särskilda stadgandena skola tolkas, och är icke berättigad att från tolkningen 
af en bestämmelse draga slutsatser, huru en annan skall förstås. Än mindre kan man drifva den meningen, att det taxeringssätt, som vunnit häfd $i$ fråga om bevillningstaxeringen, skall ovillkorligen följas vid taxering efter inkomstskatteförordningen, då dessa hvila på olika grunder.

En del nya spörsmål, som uppkommit genom inkomstskatteförordningen, kunna i själfva verket icke afgörande lösas på annat sätt än att taxeringsmyndigheterna få afgöra reella frågor, efter hvad rättvisa och billighet kräfva, och att ur deras beslut utbildas en praxis till ledning för framtiden.

Ett påpekande af oklara stadganden i den nya förordningen är till gagn särskildt därföre, att man har att emotse en omarbetning af densamma under den närmaste framtiden. Det är ju från riksdagens sida uttryckligen förklaradt, att förordningen ej är tillfredsställande och skall anses såsom provisorisk.

Här är icke tillfälle att närmare gå in på alla de punkter, där rättelse bör ske, men i detta sammanhang bör framhållas, att man genom ett stadgande, att inkomst ovillkorligen skall taxeras till det belopp, hvartill den uppgått under det förra áret, äfven om inkomsten under det löpande året blir högre eller lägre eller alldeles upphör, skulle undanröja en mängd af de svårigheter, som nu förefinnas. Ett yrkande i denna riktning förekom i en reservation till bevillningsutskottets betänkande angående inkomstskatteförordningen vid 1902 års riksdag. Samma tanke har nu upptagits af hr Davidson i en uppsats i ro:de häftet af Ekonomisk Tidskrift för detta år. Däri framhållas på ett förträffligt sätt de fördelar, som därigenom vinnas, samt erinras, att ett sådant taxeringssätt ej föranleder till någon orättvisa mot den skattskyldige, men skulle bereda honom den trygghet, att om han afgifvit en ärlig och riktig deklaration, taxeringen alltid kommer att ske $\mathrm{i}$ öfverensstämmelse med hvad han i deklarationen uppgifvit. Jag instämmer till alla delar $\mathrm{i}$ hvad hr Davidson $\mathrm{i}$ den senare uppsatsen yttrat, och det gläder mig särskildt, att tanken på konsekvent genomförande af principen om taxering efter föregående års inkomst vunnit stöd hos en statsekonom, som så mycket sysselsatt sig med studier på skatteväsendets område.

G. F. Ö. 